\title{
Measuring the eGovernment Readiness: Proposed Framework
}

\author{
Zaied Shouran \\ Computer and Electronics \\ Science \\ Department, UGM, Yogyakarta
}

\author{
Nur Rokhman \\ Computer and Electronics \\ Science \\ Department, UGM, Yogyakarta
}

\author{
Tri Kuntoro Priyambodo \\ Computer and Electronics \\ Science \\ Department, UGM, Yogyakarta
}

\begin{abstract}
Information and communication technology can make speedy changes in government processes, particularly in developing countries.in addition, there are many factors that effect on the implementation of eGovernment, because of these, this study carried out a framework to check eGovernment readiness by using the most important factors to measure eReadiness namely Technical, Organizational and Cultural. The result shows that the trust of the Internet and technology is very important to the wide-spread acceptance of eGovernment. because of that, Users need the Data and information protection must be safe from the unauthorized. Also, increasing the training and education factor will positively increase the decentralization factor. ICT infrastructure alone cannot achieve the implementation of eGovernment without a conscious policy designed to transform both the role of ICT in administration and the training and orientation of staff to imbibe innovations. it will be easier for people to be involved with new technology when all the essential things for life are covered. Computer and Internet experience impact eReadiness. public sector organizations should pay more attention to the recruitment and training of socalled big data talent or data scientists. In addition, there is a need to feel that there are benefits from requesting such a service online (perceived usefulness), on another hand, ease of use of the eGovernment website has no significant impact of eReadiness. ICT infrastructure and human capital get less weight, while indicators such as connectivity and regulations acquire more weight. This means that a country that is considered less ready in terms of ICT infrastructures and skills required to adopt eGovernment, its readiness with the new main characteristics of Cloud Computing.
\end{abstract}

\section{Keywords}

eGovernment readiness, Technical, Organizational, Cultural.

\section{INTRODUCTION}

Information and Communications Technology (ICT) development and connectivity are crucial to developing countries because they enable communications, interactions, and transactions that will allow developing countries to engage more effectively with world markets. Government services are provided through several channels, banks, post offices and so on. In these situations, technology plays a key role in services so as to enhance eGovernment infrastructure. eGovernment has become a global issue having a significant influence on all public sectors and economies; hence, there is a need for global cooperation as well as knowledge and experience exchange [1]. New technologies facilitate collaboration between people. This includes collaboration between public service agencies, within those agencies and with individuals. The interaction between service delivery stakeholders now often creates synergy between service seekers, service providers, and service facilitators. Recent decades have witnessed extensive use of Information and Communication Technologies (ICTs) by national and local governments worldwide to enhance the efficiency of governments and bring them closer to citizens' demands. eGovernment appropriation requires an abnormal state of fulfillment from both citizens and businesses. A high satisfaction level will succeed in increasing the eGovernment adoption rate. It will also ensure transparency in government operations and restore trust in governments [2]. Nonetheless, the adoption of eGovernment needs huge requirements to be met, such as that of technological readiness. through a few years ago, the eReadiness indices have undergone some modifications to reflect the transformation of the technology landscape. advancing in technologies requires assessing the impact of any emerging technology on eGovernment adoption. eGovernment readiness is an important indicator of the quality of ICT infrastructure. It is the ability of citizens to use ICT and organizations to benefit from modern technologies in a country [3]. The examination has highlights that recognize it from the existing literature. To start with, as far as anyone is concerned, this study is among the first to adopt the new framework. Second, in contrast to other research, which treats the association between these factors and eReadiness as a straight relationship or a reasonable causal linkage, in this paper contend that the relationship between Technical, Organizational and Cultural is the human resource. The rest of this paper is organized as follows. The following section outlines the study's Background. Next, the eReadiness factors that content Technical, Organizational and Cultural. From that point forward, the paper Literature review. Next, desiccation.

\section{BACKGROUND}

eGovernment refers to government systems of ICT change relations with residents, the private area and other government organizations so as to upgrade the strengthening of nationals, government proficiency and conveyance of administration, expanded straightforwardness and responsibility [4]. eGovernment refers to the capability of various government agencies to provide government information and services at any time to citizens using electronic means speedily and properly, resulting in fewer costs and effort via a single Internet site [5]. Measuring government systems' efficiency and performance are very important during this context. what is more, measurement criteria vary from country to country, counting on several parameters that are visible or generally stay invisible? They dictate implementation and management processes, if not design processes from the terrible kick-start of the programmed. eGovernment system, because it seems lucrative, is not that straightforward to implement across the countries. This brings out the question, whether the system has been designed properly supported the ground reality; whether or not the nation is capable of running or adapting eGovernment; or whether or not the country is competent enough to hold out eGovernment promotion; or whether or not the people are ready enough to regulate into the transformed environment. thence, several similar consequences, parameters, 
and terms arise, among that is one vital term that measures the capability of a government or associated enterprise in adopting eGovernment initiatives eReadiness. To befits eGovernment, one should first be eReady. Thus, eReadiness is the ability to use information and Communication Technologies (ICT) to develop one's economy and to foster one's welfare. A key indicator of eReadiness is infrastructure and in developing countries, this can be often a key challenge to the advancement of society. [6] define the concept of electronic readiness (eReadiness) as the ability of a country, company, or organizational unit to prepare, use, and take a benefit from the adoption of a new innovation, such as e-business, eGovernment, e-procurement, e-learning, etc. (Figure 1) show that specific parts of Technology, Society, and Agency governmental body as factors, which might provide a basis for redefining the remit of eGovernment analysis. although these findings are placed within sure categories for analytical functions, the 3 areas of interest are terribly closely interlinked [7]. eGovernment issues should be approached from an associate degree basically knowledge base perspective and look for active engagement from all relevant stakeholders across these given areas. Indeed, an interdisciplinary approach is important to include citizen needs and requirements considering constant organizational, technical and social modification. the necessity is to develop organizational, policy and technological structures which will adapt to change and thus, research ought to additionally focus on these characteristics. All the contributors were basically representatives of stakeholder groups. These stakeholders have to have a stronger voice within the drafting of eGovernment policies and also the development of the relevant technologies. the talk concerning participation should be connected to multiple problems, such as: (a) technology (in the sense of the fundamental infrastructure that has to be in situ); (b) education and coaching (the information the voters ought to have so as to be able to use this technology) and (c) organization (the reasonably social control structures that need to be in place so these services reach the citizen within the best possible way). Participants additionally highlighted the necessity to look at eGovernment from the angle of the entities providing the services. This specifically has to address the coordination of existing government operations or processes, and the way they ought to be organized.

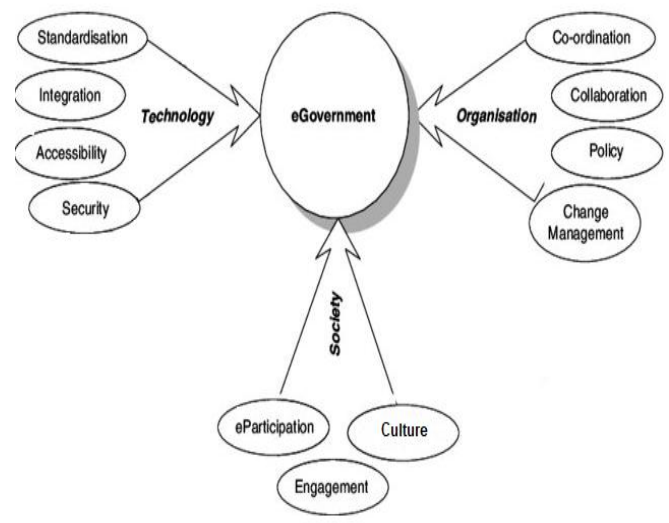

Figure 1 Diagram eGovernment [7]

\section{READINESS FACTORS}

The advancing of ICT technologies forces the governments over the world reassess their eReadiness in order to identify the most relevant IT-based development opportunities to be more efficient in providing services to their citizens. eReadiness assessment is particularly relevant for government at its preliminary or intermediate development stage of eGovernment. By reviewing the literature, readiness factors are divided into three main groups in this study, including cultural (such as: the traditional method, citizen trust in government and technology ,gap between genders, the intention to use eGovernment), technical (such as: IT standards, IT infrastructure, cooperation and coordination, security, network infrastructure, IT skills and staff), and organizational factors (such as: training, policy and legal issues, change management, implementation procedures, organizational structure, organizational culture, reward system, data privacy, data ownership, organizational vision and strategy, management commitment and management permanence).

\subsection{Technical}

Some of the most important technical factors which have been studied in the eGovernment literature is: Providing funding for citizens and eligible businesses for buying essential IT infrastructure and Establishing regulations and laws for prosecuting those who in any form abuse eGovernment services, also Supporting eGovernment related journals and magazine, Purchasing and implementing IT infrastructure in governmental organizations. The main issues identified in the technical area related to the need for flexible and scalable technology, privacy and security of available services, shared services (including common identity management), standards, coordination and integration between government services and departments, identification and authentication and impact analysis - whether on citizen or organization.

\subsection{Organizational}

Some of the most important organizational factors considered in previous studies to assess the role of organizational readiness factors in the relationship between eGovernment factors and eGovernment outcomes are: training, business process reengineering, policy and legal issues, technical staff, quality, change management, reward system, organizational structure and organizational culture [8]. Training, policy and legal issues, change management, implementation procedures, organizational structure, organizational culture, reward system, data privacy, ownership of data, organizational vision and strategy, management commitment, and rate of turnover were fed into organizational factors. The main groups of issues raised included: interaction between and across government departments; coordination and ownership issues between agencies and departments; political engagement, policy making and the mandate to deliver automated, technology-supported services; project management of eGovernment initiatives; in particular, change management issues; management of risk and knowledge so as to optimize and learn from eGovernment experiences and metrics for measuring and evaluating organizational performance and capabilities.

\subsection{Cultural}

One key to the success of government transformation is the development of the individual's culture. also defines culture as the collective programming of the mind which distinguishes the members in one human group from another. Others as inform that culture is a critical variable in explaining how social groups interact with IT [9]. The main issues identified under the social heading related to the citizen and civil society. They included engagement with citizens, government authorities and other stakeholders; considering 'social value added', the need for a citizen-centric process, take-up of eGovernment services and incentivizing and diversity of different socioeconomic. 


\section{PROPOSED FRAMEWORK}

eReadiness of governments has become a key policy tool for any country since it opens the way before of the citizens to move with the government and enhances their trust that successively advances the economic efficiency and business. therefore, eReadiness is turning into additional accepted at the level of governments, organizations, and citizens. eReadiness throughout this paper is printed as a result of the availability of the required physical infrastructure (high information measure, responsibility, and cheap prices); access to data (software information system); availableness of devices needed to access data (hardware and network availability and Survivability); degree to that the ICT master plans and policies address the vision of an organization, the protection level adopted by the organization and additionally the human resource to use and manage these resources for the implementation of eGovernment. although there are several e-Readiness assessment tools, there are not any fixed tips on however these tools will be applied effectively as models in implementing eGovernment assessment environments. style of eGovernment readiness assessment models needs a fathomable measurement of the evaluation structure that decides factors plainly got from information. eGovernment readiness should not only be examined from a technological perspective; but additionally, a more comprehensive, integrative approach, that accommodates organizational and cultural perspectives, is needed to advance information during this domain. on the far side any doubt, while not a transparent and coherent understanding of what motivates the overall public to use eGovernment services, governments would not be able to make informed strategic decisions to increase the eGovernment adoption and use. Therefore, the research focuses on 3 eGovernment readiness factors and make comprehensive framework.

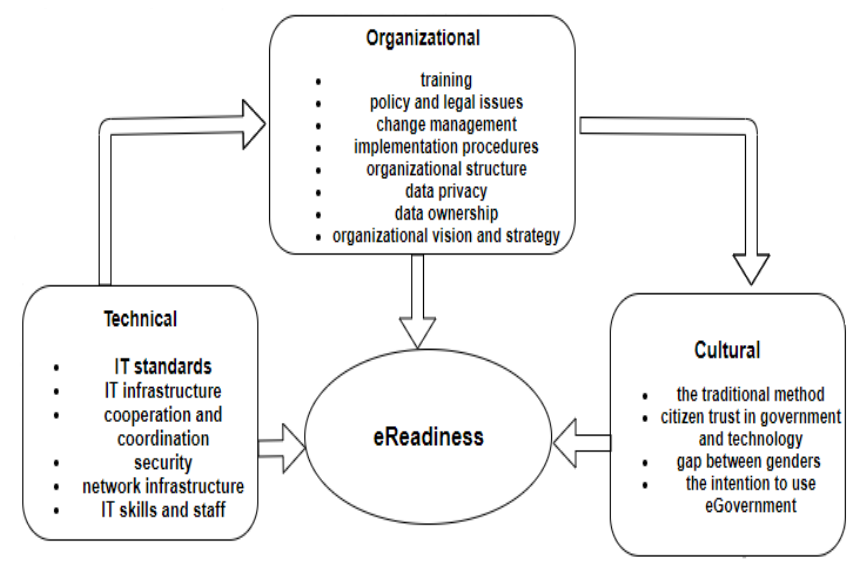

Figure 2 eReadiness measuring framework

\section{LITERATURE REVIEW}

\subsection{Technical}

[10] present that the e-readiness indices have undergone some modifications to reflect the transformation of the technology landscape. Consequently, the continues advancing in technologies needs assessing the impact of any rising technology on eGovernment adoption. [11] said that the high impact of the technology infrastructure eReadiness emphasizes that technology is that the main supply of modification and provides power for enabling the method of implementing eGovernment initiatives. [12] The result showed that there's a positive important relationship between technological readiness and also the IT competencies of Iraqi accountants. and it implies that the technology readiness relating to willingness, enthusiasm, and motivation of accountants using it's an impact on their IT competencies. In alternative words, the higher the eReadiness of the accountants in creating use of technology, the upper their competency within the use of IT. [13] see that the Dutch public sector wasn't entirely prepared for the largescale introduction of big data and will further develop its readiness for big data use. [14] claim that It is clear that the experience with computer and Internet will raise the ereadiness to use eGovernment where the computer and the Internet are its main media. [15] see that the active promotion of open data-driven and civic engagement projects and platforms have the potential to the event of eGovernment readiness, there ought to be the lack of adequate infrastructure in several developing nations which can be an obstacle in setting the worldwide comes. [16] highlighted that ICT may be an important issue for SMEs eGovernment adoption. [10] [17] show how Cloud Computing can refine the existing eGovernment readiness indices; so that indicators like ICT infrastructure and human capital get less weight, while indicators such as connectivity and regulations acquire more weight. [1] claim that The survey demonstrated that there is an absence of examination and assertion about the factors that shape the technological aspects of eGovernment readiness; hence, a clear gap is distinguished as existing in the current knowledge on the technological aspects of eGovernment readiness. [18] highlighted that the result reveals that the respondents' rating of their access to ICT is low. Also, the result reveals that the respondents perceived the standard of ICTs in BARDA as being poor. the general eReadiness index of the BARDA shows that the agency is barely ready for maximization of the ICTs. Since the advantages that arise from ICT depends on the degree to that such work is prepared, willing or ready to get these advantages. This result shows that the BARDA may not be ready to access the advantages of obtainable within the electronic world like cost effectiveness in service delivery.

\subsection{Cultural}

[9] claim that the government, people and agencies cultural factors are more important than technological factors to implement eGovernment systems successfully. This is because the culture of accepting new technology is a critical issue that affects the success or failure of the eGovernment project. [19] shows that all five factors, namely: performance expectancy, effort expectancy, social influence, facilitating conditions and behavioral intention have a significant effect on the adoption of eGovernment services in Jordan. [14] the respondents do not prefer the traditional method (face to face) due to the long routine. The findings also show the impact of the income on eReadiness. Facilitating conditions is also affected by income. Also argued about culture on eReadiness, the impact of gender is obvious. Females are less e-ready according to all the scales except the era equipment scale where most respondents agree with it. This gap between genders in eReadiness is due to Yemeni culture where it offers more chance for males in education, job, income, and experience in computers and the Internet. [16] see that Culture issue had considerably influenced the intention of SMEs to use eGovernment services.

\subsection{Organizational}

[11] said that eGovernment should be nationally orientated. In general, lack of competency of government staff in using ICT, low level of eGovernment awareness among the voters and lack of motivation are the most important obstacles for the roaring implementation of eGovernment at the municipal level. [20] highlighted that the eReadiness on the part of the citizens looks to be terribly high. On an average, seventy-nine and have access to some or the opposite device which may lead to a great 
success leading towards $\mathrm{G} 2 \mathrm{C}$ based mostly initiatives. the government might use this accessibility to increase its reach. [14] argued about Trust Expectancy, it can be noticed that the weakness came from the items that indicate information security. The findings also show Effort Expectancy scales that there is some hesitation for using eGovernment according to the effort. [21] argued that citizen awareness is required in implementing eGovernment practices. [13] said that the organizations which assessed did not seem to totally understand that big data applications would add price to their organizations only if they supported and were supported by all the main organizational activities. not like organizations within the private sector, wherever big data will unlock new possibilities and enable new goals. [22] and [13] see that Public organizations should not start using big data before they are ready, as that could unleash big data's darker side. Breaches of privacy and security of personal data, unfair treatment of citizens through overly extensive and unethical datafication of decision-making processes, wrong or suboptimal decisions because of incorrect data handling, analyses and interpretation, inadequate and faulty IT facilities and large IT investments that never pay off are just a few of the dangers.[16] see that Management Awareness is taken into account to be the foremost important issue affecting SMEs intention to adopt eGovernment services.[23] highlighted that the major obstacles to successful technology adoption in Iranian corporations are: lack of human resources professionals, serious social control issues, low investment in $R \& D$, the issues of operating with suppliers, the shortage of specialized education and training, lack of motivation in workers and poor ability in tiny and medium corporations to absorb technology. [24] said that Government and elected officials must be ready to change their mindset and place value on the opinions of local citizens; on the opposite hand, local voters must be ready to change their attitude of passive recipients and come forward with their knowledge and share resources of government. [25] shows that the challenges mainly emanate from lack of adequate funding, the dearth of expertise, glaring obsolescence and legacy systems residing in various ministries. Also, The absence of IT strategy pervades all the ministries studied and show how ICT infrastructure alone cannot achieve the implementation of eGovernment without a conscious policy designed to transform both the role of ICT in administration and the training and orientation of staff to imbibe innovations.[26] highlighted that Government web-based interface ought to be surveyed in light of the fact that it is rising as a key need for public sector organizations, as they build up their eGovernment activity and make electronic interaction between users.

Tabel 1 eReadiness factors Comparison

\begin{tabular}{|c|r|r|r|}
\cline { 2 - 4 } \multicolumn{1}{c|}{} & \multicolumn{3}{c|}{ factors } \\
\hline authors & Technical & Cultural & Organizational \\
\hline$[10]$ & $\checkmark$ & & \\
\hline$[11]$ & $\checkmark$ & & \\
\hline$[12]$ & $\checkmark$ & & \\
\hline$[13]$ & $\checkmark$ & & \\
\hline$[14]$ & $\checkmark$ & $\checkmark$ & \\
\hline$[15]$ & $\checkmark$ & $\checkmark$ & \\
\hline$[16]$ & $\checkmark$ & & \\
\hline$[17]$ & & & \\
\hline
\end{tabular}

\begin{tabular}{|c|c|c|c|}
\hline${ }^{[1]}$ & $\checkmark$ & & \\
\hline$[18]$ & $\checkmark$ & & $\checkmark$ \\
\hline$[20]$ & & & $\checkmark$ \\
\hline$[21]$ & & & $\checkmark$ \\
\hline$[22]$ & & & $\checkmark$ \\
\hline$[13]$ & & & $\checkmark$ \\
\hline$[23]$ & & & $\checkmark$ \\
\hline$[25]$ & & & $\checkmark$ \\
\hline$[26]$ & & & \\
\hline$[24]$ & & & \\
\hline$[9]$ & & $\checkmark$ & \\
\hline$[19]$ & & $\checkmark$ & \\
\hline
\end{tabular}

\section{DISCUSSION}

It seems to the authors that one dimension may affect on the eReadiness of eGovernment implantation is people culture. citizen trust in government and technology (trust of the Internet) is very important to the wide-spread acceptance of eGovernment as well as trust in the reliability of the enabling technology. also, the degree of decentralization is positively related to educational attainment. Therefore, increasing the training and education factor will positively increase the decentralization factor. On the other hand, the structure factor is considered here as a cultural factor of the public agencies and the managers themselves. The reduction of the gap between Project Management and Knowledge Management can indicate more balancing between hardcore technical components such as ICTs and soft components such as people, information, and processes, and thus can be considered an advance towards the reduction of the digital divide. ICT infrastructure alone cannot achieve the implementation of eGovernment without a conscious policy designed to transform both the role of ICT in administration and the training and orientation of staff to imbibe innovations. there is a positive significant relationship between technological readiness and the IT competencies, the technology readiness regarding willingness, enthusiasm, and motivation of accountants using IT has an impact on their IT competencies. eGovernment organizational strategy contemplations are vital to approve costs and to guarantee the dimension to which dreams and objectives are practiced, and to perceive conceivable difficulties, for example, technological, and online policy. Guaranteeing compatibility with an eGovernment program, providing an action plan, and checking these objectives by guiding board of trustees is huge.

Government and elected officials need to be ready to change their mindset and place value on theopinions of local citizens; on the other hand, local citizens need to be ready to change their attitude of passive recipients and come forward with their knowledge and share resources of government. in that along with the governmental office's readiness, readiness for establishing eGovernment also depends on collaborative activities among all local stakeholders in public service delivery. assessing the status of collaborative action can be of significance to represent accurate eReadiness of all actors, eGovernment officials, elected leaders, business associations and local citizens for establishing a new government system. 
Education impacts the eReadiness in a great manner. It has been noticed that the higher educated are more eReady than the less educated. It could be concluded that education is one of the most important elements that support eReadiness. Whenever income is increasing, the eReadiness increases. It can be concluded that high income supports eReadiness in many ways, for example, the ability to own PC and Internet access, the ability to enter courses for computer experience and Internet knowledge. In general, it will be easier for people to be involved with new technology when all the essential things for life are covered. Computer and Internet experience impact eReadiness. It is clear that the experience with computer and Internet will raise the eReadiness to use eGovernment where the computer and the Internet are its main media.

Big data offers a great opportunity for the public sector to structurally improve and transform government organizations. public sector organizations should pay more attention to the recruitment and training of so-called 'big data talent' or data scientists. to the benefit of current data activities as well as the big data readiness of the organization and the successful utilization of big data applications in the future [13].

The study found that ICT is a significant factor for the SMEs eGovernment adoption Having computers and internet connections are essential factors for SMEs to be ready to adopt eGovernment services. However, ICT alone is not enough, but it needs to be combined with the Readiness of the between SMEs' employees and managers (human capital) as it has the upper hand and towards deciding to adopt eGovernment services or not. This is because their capabilities to use computers and the internet encourage them to request services online. Also, Top Management Awareness is considered to be the most influential factor affecting SMEs intention to adopt eGovernment services. The awareness between managers that they can get government services via the eGovernment portal is the first step to move forward to adopt eGovernment. Nevertheless, awareness should be Once managers are ready and aware of the eGovernment services, there is a need to feel that there are benefits from requesting such a service online (perceived usefulness). Therefore, the government has to provide a certain number of services that SMEs mostly need such as filling tax forms online. On the contrary, ease of use of the eGovernment website has no significant impact on adoption. Culture factor has affected also. SMEs still prefer face-to-face interactions. The reason is that any government transaction is based on a paper form which is signed and stamped so it could be accepted for further transactions with other government organizations. There are difficulties for SMEs to believe that documents they receive online are equal to the traditional method. Trust was not supported. The explanation for this is that users have to request services from the government regardless of the degree of trust. The main challenge of implementing eGovernment not only improves the efficiency of public services but also strengthens the trust and openness among the government administrators with their society through the exchange of relevant information [27].

The characteristics of the Cloud Computing and its expected benefits in the public sector encourage governments to adopt these technologies, especially in the developing countries where the cost is one of the major barriers for implementing advanced IT infrastructures that indicators like ICT infrastructure and human capital get less weight, while indicators such as connectivity and regulations acquire more weight. This means that a country that is considered less ready in terms of ICT infrastructures and skills required to adopt eGovernment, its readiness with the new main characteristics of Cloud Computing, benefits and challenges to eGovernment can be concluded [17].

Training programs for citizens can be the most effective way to introduce the advantages of eGovernment services. Also, effective and efficient laws and regulations can help citizens learn how to utilize such services. Furthermore, given the importance of 'organizational factors. Lack of awareness about the benefits of eGovernment remains a critical factor in user adoption in developing countries. Many factors, such as education, race, and culture have contributed to a low level of user awareness. also, some clusters of society had considerably lower awareness about eGovernment. Meanwhile, building trust among citizens toward eGovernment services was most essential for eGovernment success. Users need to be assured of the legitimacy and authenticity of eGovernment services, and that personal details processed online are secured with confidentiality remaining intact.

\section{CONCLUSION}

An eGovernment ready country is one that has: the national ICT policy and regulative environment; physical infrastructure (high information measure, responsibility), telecommunication and ICT infrastructure (critical infrastructure and cybersecurity), status of national cybercrime laws, status of electronic signature legislation; integrated current ICT throughout businesses (e-commerce, ICT sector); human capital (quality of education and technology skills, information economy growth), and communities (applications using open data, organizations online, ICT employed in everyday life). People eReadiness is very vital once organizations bear a transition period, such as the introduction of the latest technology. People play major roles in determining the success and failure of an organization; regardless of how big or small their roles might be [28]. it is important to make sure that people are well prepared and ready for the changes [29]. When people in organizations are ready, they are more likely to positively participate in the changes, thus contribute to its success [30]. Findings show that the trust of the Internet and technology is very important to the wide-spread acceptance of eGovernment. because of that, Users need the Data and information protection must be safe from the unauthorized. Also, increasing the training and education factor will positively increase the decentralization factor. ICT infrastructure alone cannot achieve the implementation of eGovernment without a conscious policy designed to transform both the role of ICT in administration and the training and orientation of staff to imbibe innovations. it will be easier for people to be involved with new technology when all the essential things for life are covered. Computer and Internetexperience impact eReadiness. public sector organizationsshould pay more attention to the recruitment and training ofso-called 'big data talent' or data scientists. In addition, there isa need to feel that there are benefits from requesting such a service online (perceived usefulness), on another hand, ease ofuse of the eGovernment website has no significant impact ofeReadiness. ICT infrastructure and human capital get less weight, while indicators such as connectivity and regulations acquire more weight. This means that a country that isconsidered less ready in terms of ICT infrastructures and skills required to adopt eGovernment, its readiness with thenew main characteristics of Cloud Computing. Future workshould involve all major eReadiness aspects that describe all indicators for each factor used in this study. 


\section{REFERENCES}

[1] M. O. M. Baeuo, N. Z. B. Ab. Rahim, and A. A. M Alaraibi, "Technology Aspects of E-Government Readiness in Developing Countries: A Review of the Literature," Comput. Inf. Sci., vol. 9, no. 4, p. 1, 2016.

[2] M. H. Bin Othman and R. Razali, "Key contributing factors towards successful Electronic Government systems interoperability," in International Conference on Research and Innovation in Information Systems, ICRIIS, 2013.

[3] R. Máchová and M. Lněnička, "Reframing E Government Development Indices with Respect to New Trends in ICT," vol. 15, no. 4, pp. 383-411, 2015.

[4] G. Karokola, S. Kowalski, and L. Yngström, "Evaluating a framework for securing e-government services - A case of Tanzania," in Proceedings of the Annual Hawaii International Conference on System Sciences, 2013.

[5] A. M. Odat, "E-Government in Developing Countries Framework of Challenges and Opportunities," vol. 46, no. 2, pp. 1013-1021, 2012.

[6] S. E. Oberfield et al., "E-Readiness: How Ready Are Uk Construction Organizations To Adopt It," J. Acquir. Immune Defic. Syndr., vol. 7, no. 1, pp. 57-62, 2010.

[7] T. Elliman and P. Jackson, "Electronic Transformation of Government in the U.K.: A Research Agenda," no. November 2014, 2007.

[8] A. Keramati, I. Behmanesh, and H. Noori, "Assessing the impact of readiness factors on e-government outcomes: An empirical investigation," Inf. Dev., vol. 34, no. 3, pp. 222-241, 2018.

[9] A. Sabri, O. Sabri, and B. Al-shargabi, "A Cultural EGovernment Readiness Model," Intell. Inf. Manag. http//www.SciRP.org/journal/iim, vol. 4, no. September, pp. 212-216, 2012.

[10] F. Mohammed and O. Bin Ibrahim, "Drivers of egovernment readiness indices modifications," Int. J. Electron. Gov., vol. 7, no. 3, p. 186, 2015.

[11] S. Joseph and O. O. Olugbara, "Evaluation of municipal egovernment readiness using structural equation modelling technique," J. Transdiscipl. Res. South. Africa, vol. 14, no. 1 , pp. 1-10, 2018

[12] H. H. K. Alkhaffaf and A. Abdullah, "the Influence of Cognitive Factors on Information Technology Competencies Among Accountants in Civil Conflict Environment :," vol. 2, no. 2, pp. 13-30, 2017.

[13] B. Klievink, B. J. Romijn, S. Cunningham, and H. de Bruijn, "Big data in the public sector: Uncertainties and readiness," Inf. Syst. Front., vol. 19, no. 2, pp. 267-283, 2017.

[14] A. Amirat and M. Oussalah, "The Impact of the Culture on the E-Readiness for E-Government in Developing Countries (YEMEN)," 13th Int. Arab Conf. Inf. Technol., no. January, 2012.

[15] [15] R. Machova, "the Assessment of E-Government Readiness in the Globalization Process," Glob. Its SocioEconomic Consequences, 16Th Int. Sci. Conf.
Proceedings, Pts I-V, no. January, pp. 1244-1251, 2016.

[16] H. Abdelghaffar and I. Elmessiry, "SME's Readiness for e-Government Services: The Case of Egypt.," J. EGovernance, vol. 35, no. 4, pp. 186-194, 2012.

[17] F. Mohammed and O. Ibrahim, "Refining E-government Readiness Index by Cloud Computing," J. Teknol. (Sciences Eng., vol. 65, no. 1, pp. 23-34, 2013.

[18] M. O. Olaolu, E. A. Agwu, P. D. Ivande, and T. A. Olaolu, "E-readiness of public extension personnel for service delivery in Benue State, Nigeria," J. Agric. Ext., vol. 22 , no. 2,2018

[19] A. A. Rabaa'i, "The use of UTAUT to investigate the adoption of e-government in Jordan: a cultural perspective,” Int. J. Bus. Inf. Syst., vol. 24, no. 3, p. 285, 2017.

[20] K. S. Vaisla and D. Pant, "Government To Citizen ( G2C ) E- Readiness of Uttarakhand," J. Comput. Technol., vol. 1, no. 2, 2012.

[21] M. B. Kayani, M. E. Haq, M. R. Perwez, and H. Humayun, "Analyzing Barriers in e-Government Implementation in Pakistan," Int. J. Infonomics, vol. 4, no. 3, pp. 494-500, 2011

[22] M. Janssen and J. van den Hoven, "Big and Open Linked Data (BOLD) in government: A challenge to transparency and privacy?," Gov. Inf. Q., 2015.

[23] F. Moztarzadeh, M. R. G. Nezhad, J. Salimi, and A Beynaghi, "Technology Readiness in Iran," no. January, 2012.

[24] W. Waheduzzaman and S. J. Miah, "Readiness assessment of e-government: a developing country perspective," Transform. Gov. People, Process Policy, vol. 9, no. 4, pp. 498-516, 2015.

[25] A. F. Hamajoda, "An E-readiness Survey of Selected Federal Ministries in Nigeria for Freedom of Information and E-government Implementation .," no. April, 2018.

[26] I. A. Alghamdi, R. Goodwin, and G. Rampersad, "EGovernment Readiness Assessment for Government Organizations in Developing Countries," Comput. Inf. Sci., vol. 4, no. 3, pp. 3-17, 2011.

[27] T. K. Priyambodo and Y. Prayudi, "Information security strategy on mobile device based egovernment," ARPN J. Eng. Appl. Sci., vol. 10, no. 2, pp. 652-660, 2015.

[28] M. R. Muhammad, "Managing the implementation of egovernment in Malaysia: a case of E-Syariah," Aust. J. Basic Appl. Sci., vol. 7, no. 8, pp. 92-99, 2013.

[29] A. A. Ogunyemi, K. A. Johnston, and K. Johnston, "Exploring the roles of people, governance and technology in organizational readiness for emerging technologies," African J. Inf. Syst., vol. 4, no. 3, pp. 99$119,2012$.

[30] Q. Tran, D. Huang, B. Liu, and H. M. Ekram, "A Construction Enterprise's Readiness Level in Implementing E-Procurement: A System Engineering Assessment Model," Syst. Eng. Procedia, vol. 2, pp. 131$141,2011$. 